\title{
Skull sclerosing epithelioid fibrosarcoma: A case report and review of the literature
}

\author{
JINGJING XU ${ }^{1}$, JIAWEI WANG ${ }^{1}$, MINMING ZHANG ${ }^{1}$ and BAIZHOU LI $^{2}$ \\ Departments of ${ }^{1}$ Radiology and ${ }^{2}$ Pathology, The Second Affiliated Hospital, \\ School of Medicine, Zhejiang University, Hangzhou, Zhejiang 310009, P.R. China
}

Received February 26, 2015; Accepted March 10, 2016

DOI: $10.3892 / \mathrm{ol} .2016 .4385$

\begin{abstract}
Sclerosing epithelioid fibrosarcoma (SEF) is an unusual variant of fibrosarcoma that was previously considered to be a low-grade tumor with an indolent course. The tumor occurs most commonly in the soft tissue of the limb, trunk, head and neck, and occasionally in the bone and visceral organs. The skull is a rare primary site for SEF, with only 3 cases reported to date. The current study reports a case of SEF occurring in the occipital bone of a 24-year-old man, who lacked neurological symptoms. Imaging revealed a large mass emanating from the occipital bone and involving the superior sagittal sinus, torcular herophili and adjacent brain tissue. Histological and immunohistochemical characteristics confirmed the diagnosis of SEF. The patient experienced local recurrence and distant metastasis at 10 and 15 months, respectively, subsequent to the resection of the primary mass. The current case and review of the literature suggest that skull SEF may behave clinically as an aggressive malignant sarcoma. Radiological findings indicated the biological and histopathological characteristics of the tumor. Thus, its clinical behavior and certain imaging features may suggest this diagnosis.
\end{abstract}

\section{Introduction}

Sclerosing epithelioid fibrosarcoma (SEF) is a low-grade variant of fibrosarcoma, which was first described by Meis-Kindblom et al (1) in 1995 as a rare but clinicopathologically distinct tumor of the soft tissue. The tumor occurs primarily in the extremities, trunk, head and neck, and less commonly in the bone and visceral organs (2). Fewer than 100 cases of SEF have been reported, with only 3 previously

Correspondence to: Dr Jiawei Wang, Department of Radiology, The Second Affiliated Hospital, School of Medicine, Zhejiang University, 88 Jiefang Road, Hangzhou, Zhejiang 310009, P.R. China

E-mail: 20518154@zju.edu.cn

Key words: sclerosing epithelioid fibrosarcoma, occipital bone, skull, computed tomography, magnetic resonance imaging described in the skull (2). The depiction of its radiological characteristics is available only in a few scattered case reports and series in the pathology literature.

The current study reports the case of a patient with SEF arising from the occipital bone. To the best of our knowledge, this is the first full description of skull SEF, including its complete clinical course, imaging findings on computed tomography (CT) and magnetic resonance imaging (MRI), and pathological association; although the clinical manifestations, clinical course and histopathology of skull SEF have been previously reported, its appearances on CT, MRI and magnetic resonance (MR) venography have not.

\section{Case report}

A 24-year-old Chinese man presented with a 1-year history of a slowly enlarging and painless mass in the occiput, which was found incidentally by self-examination. The patient developed significant dizziness for 5 days, and was referred to the Neurosurgery Department of the Second Affiliated Hospital of the School of Medicine, Zhejiang University (Hangzhou, China) in December 2011 for therapy. A large, firm, non-tender mass was palpated on physical examination. The patient's past medical history was unremarkable. Neurological examination and laboratory investigation revealed normal results.

CT imaging (SOMATOM Sensation 16; Siemens Healthcare $\mathrm{GmbH}$, Erlangen, Germany) demonstrated an oval-geographic, osteolytic lesion within the squamous part of the occipital bone, with a well-demarcated intracranial, calvarial and extracalvarial soft tissue mass (Fig. 1). MRI (Signa HDxt 1.5T; GE Healthcare, Fairfield, CT, USA) revealed a focal, $5.0 \times 4.5 \times 3.5-\mathrm{cm}$ mass with bilateral occipital lobe invasion. The mass exhibited hypo- and iso-signal intensity on T1-weighted imaging and mixed-signal intensity on T2-weighted imaging. Gadolinium-enhanced images revealed prominent perilesional enhancement, particularly in the region adjacent to the brain. Irregular hypointense areas within the mass were visible on T2-weighted imaging, without obvious enhancement (Fig. 2). MR venography (Sonata 1.5T; Siemens Healthcare $\mathrm{GmbH}$ ) was also applied to evaluate the cerebral vein system. MR venography and MRI indicated that the superior sagittal sinus and torcular herophili had been invaded, and associated vasogenic cerebral edema due to mass effect was noted (Figs. 2 and 3). 

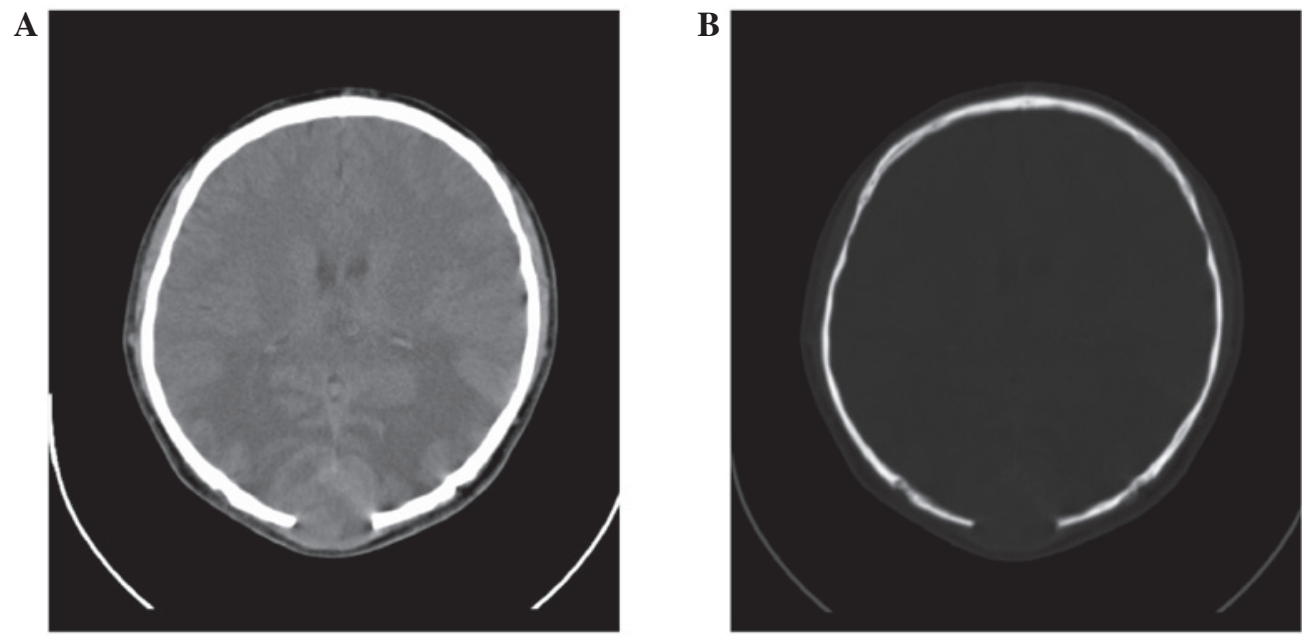

Figure 1. Axial computed tomography imaging of the brain. (A) Soft tissue window images demonstrated a well-demarcated, intracranial, calvarial and extracalvarial soft tissue mass. (B) Bone window images revealed an oval-geographic osteolytic lesion arising from the occipital bone. No bony sclerosis or periosteal reaction was observed.

A

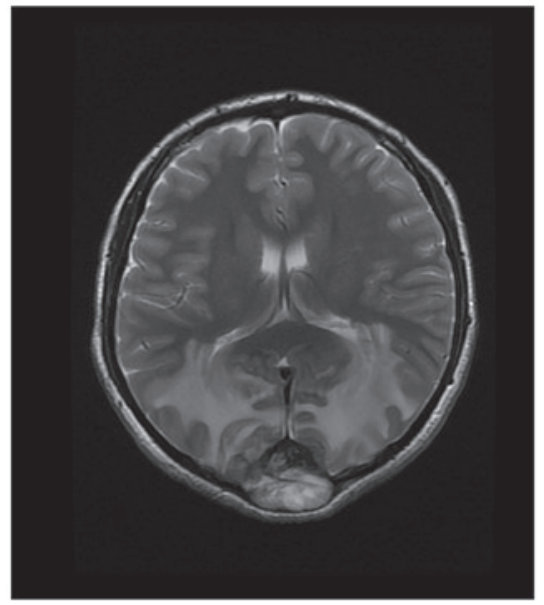

B

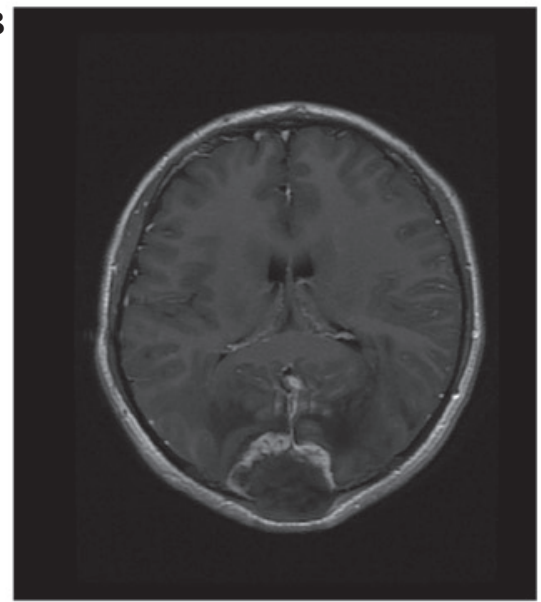

$\mathbf{C}$

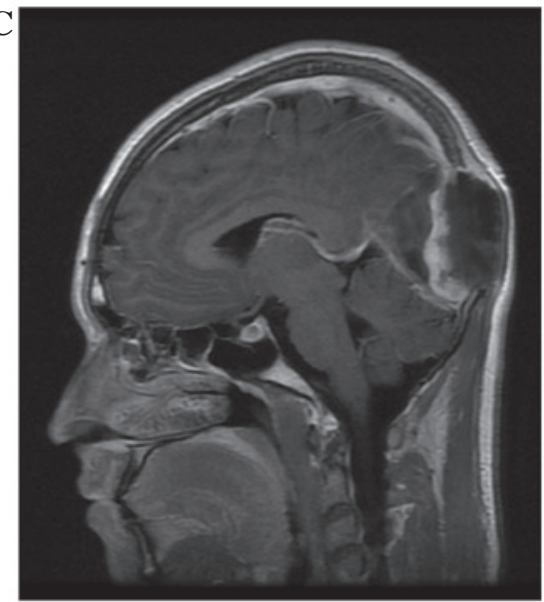

Figure 2. Magnetic resonance imaging. (A) Axial T2-weighted images revealed irregular low signal intensity within the mass and cerebral edema in bilateral occipital lobes. (B) Axial and (C) sagittal gadolinium-enhanced images revealed prominent perilesional enhancement, particularly in the region adjacent to the brain.

The preoperative diagnosis was invasive meningioma, and the patient underwent a craniotomy with subtotal tumor resection. Gross pathological examination revealed a 5.0x4.0x3.0-cm, heterogeneous mass, part of which was rich in blood supply and appeared as gray-red fragment of tissue. Resected tissues were paraffin (Fuzhou Maixin Biotech. Co., Ltd., Fuzhou, China)embedded, fixed in 10\% buffered-formalin (Fuzhou Maixin Biotech. Co., Ltd.), cut into 3-5 $\mu \mathrm{m}$ sections and stained with hematoxylin and eosin (Fuzhou Maixin Biotech. Co., Ltd.). Histological examination of the tumor following hematoxylin and eosin staining revealed cells arranged in nests or clusters, some with a central open area, that were separated by prominent collagen bands. The cells had scant to moderate cytoplasm and generally round nuclei with moderately hyperchromatic chromatin. A sizeable area of ischemic necrosis was present, comprising $\sim 50 \%$ of the tissue sections (Fig. 4). Immunohistochemical staining with the following monoclonal antibodies (ZSGB-Bio, Beijing, China) for $30 \mathrm{~min}$ at room temperature was also performed: Mouse anti-CD99 (\#ZM-0296; dilution 1:100-1:200), mouse anti-CD34 (\#ZM-0046; 1:100-1:200), mouse anti-CD10 (\#ZM-0283, 1:100-1:200; rabbit anti-CD1a (\#ZA-544; 1:100-1:200); mouse anti-CD31 (\#ZM-0044; 1:50-1:100); rabbit anti-F8 (\#ZA-0543; 1:100-1:200); mouse anti-Myogenin (\#ZM-0402; 1:25-1:50); HMB45 (\#ZM-0187; 1:100-1:200); mouse anti-P63 (\#ZM-0406; 1:100-1:200); mouse anti-epithelial membrane antigen (EMA;\#ZM-0095; 1:100-1:200); mouse anti-S100 (\#ZM-0224; 1:100-1:200); mouse anti- $\alpha$-smooth muscle actin (\#ZM-0003; 1:50-1:200); mouse anti-glial fibrillary acidic protein (GFAP; \#ZM-117; 1:100-1:200); mouse anti-cytokeratin (AE1/AE3) (\#ZM-0069; 1:100-1:200); mouse anti-vimentin (\#ZM-0260; 1:100-1:200); mouse anti-Ki-67 (\#ZM-0167; 1:200); and rabbit anti-myogenic differentiation 1 (MyoD1; \#ZA-0585; 1:100). This revealed that the lesional cells were negative for HMB45, P63, EMA, S-100, $\alpha$-smooth muscle actin, GFAP, cytokeratin (AE1/AE3), CD99, CD34, CD10, CD1a, CD31, F8, myogenin and MyoD1, and positive for vimentin. The Ki-67 staining index was estimated to be $10-15 \%$ focally, and $5-10 \%$ overall. A fluorescence in situ hybridization study revealed no rearrangement of the FUS gene. A diagnosis of SEF was subsequently determined. 
Table I. Clinical features of 4 skull sclerosing epithelioid fibrosarcomas (SEFs).

\begin{tabular}{|c|c|c|c|c|c|c|c|c|}
\hline Author & $\begin{array}{l}\text { Age, years } \\
\text { /gender }\end{array}$ & Site & $\begin{array}{l}\text { Size, } \\
\mathrm{cm}\end{array}$ & $\begin{array}{l}\text { Type of } \\
\text { surgery }\end{array}$ & $\begin{array}{l}\text { Time } \\
\text { to } \mathrm{LR}^{\mathrm{a}}\end{array}$ & $\begin{array}{l}\text { Time to } \\
\text { METS }^{\mathrm{a}} \\
\text { (location) }\end{array}$ & Follow-up ${ }^{a}$ & Refs. \\
\hline \multirow[t]{3}{*}{ Antonescu et al } & $14 / \mathrm{F}$ & $\begin{array}{l}\text { Right posterior fossa, } \\
\text { supra-tentorial space, } \\
\text { temporal bone }\end{array}$ & 6.7 & $\begin{array}{l}\text { Subtotal } \\
\text { craniotomy }\end{array}$ & - & $\begin{array}{l}35 \text { mo } \\
\text { (bone, } \\
\text { lung) }\end{array}$ & $\begin{array}{l}\text { DOD, } \\
47 \mathrm{mo}\end{array}$ & (2) \\
\hline & $52 / \mathrm{F}$ & $\begin{array}{l}\text { Right frontoparietal } \\
\text { area, intra-extra } \\
\text { cranial, bone }\end{array}$ & 6 & WLE & $12 \mathrm{mo}$ & $\begin{array}{l}13 \text { mo } \\
\text { (bone) }\end{array}$ & $\begin{array}{l}\text { DOD, } \\
26 \mathrm{mo}\end{array}$ & \\
\hline & $41 / \mathrm{F}$ & Skull base & $>15$ & WLE & 46 mo & - & $\begin{array}{l}\text { AWD, } \\
65 \mathrm{mo}\end{array}$ & \\
\hline Present case & $24 / \mathrm{M}$ & $\begin{array}{l}\text { Occipital area } \\
\text { intra-extra cranial, } \\
\text { occipital bone }\end{array}$ & 5 & $\begin{array}{l}\text { Subtotal } \\
\text { craniotomy }\end{array}$ & $10 \mathrm{mo}$ & $\begin{array}{l}15 \mathrm{mo} \\
\text { (lung) }\end{array}$ & $\begin{array}{l}\text { DOD, } \\
24 \text { mo }\end{array}$ & \\
\hline
\end{tabular}

${ }^{\mathrm{a} C a l c u l a t e d ~ f r o m ~ t i m e ~ o f ~ h i s t o l o g i c a l ~ d i a g n o s i s . ~ F, ~ f e m a l e ; ~ M, ~ m a l e ; ~ W L E, ~ w i d e ~ l o c a l ~ e x c i s i o n ; ~ L R, ~ l o c a l ~ r e c u r r e n c e ; ~ m o, ~ m o n t h ; ~ M E T S, ~}$ metastasis; DOD, died of disease; AWD, alive with disease.

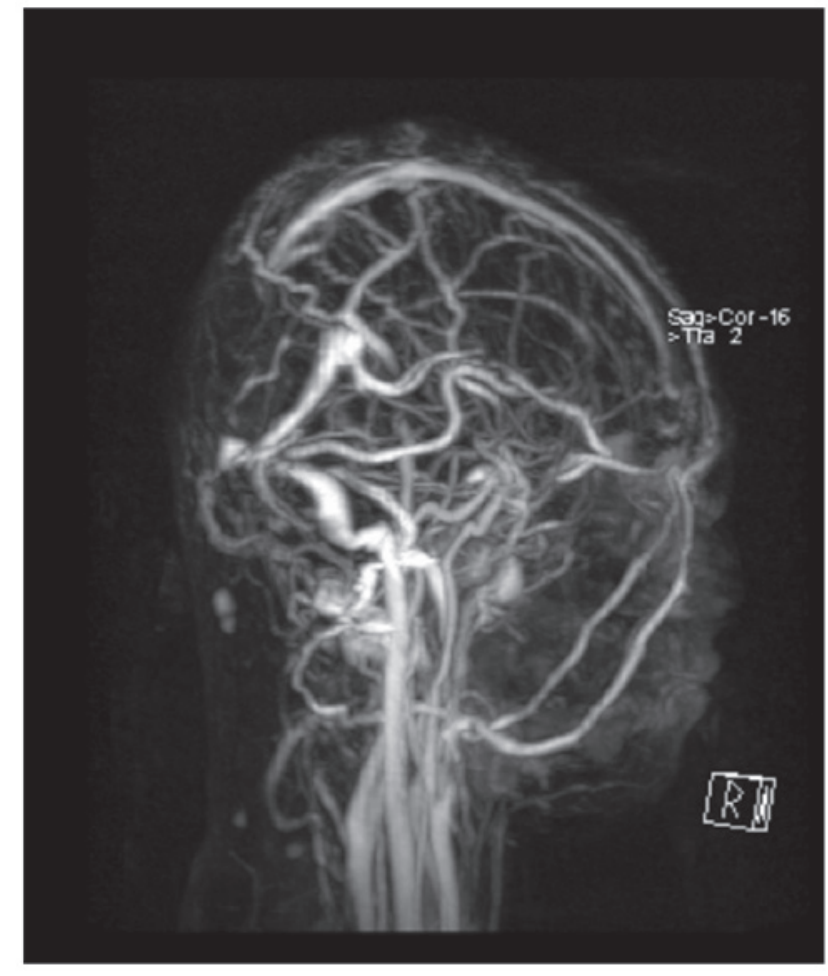

Figure 3. Brain magnetic resonance venography demonstrated a filling defect in the superior sagittal sinus and torcular herophili.

The patient was treated with one cycle of postoperative chemotherapy (ifosfamide, 2 g/day, days 1-4; etoposide $0.1 \mathrm{~g} /$ day, days 1-5). At 10 months post surgery, follow-up MRI of the original site revealed tumor recurrence. A chest CT scan performed 15 months after the surgery demonstrated multiple nodules in the bilateral lungs, suggesting metastasis. After considering the option of radiotherapy, the patient decided on palliative care only due to financial reasons, and succumbed to the disease 3 years after his initial presentation.
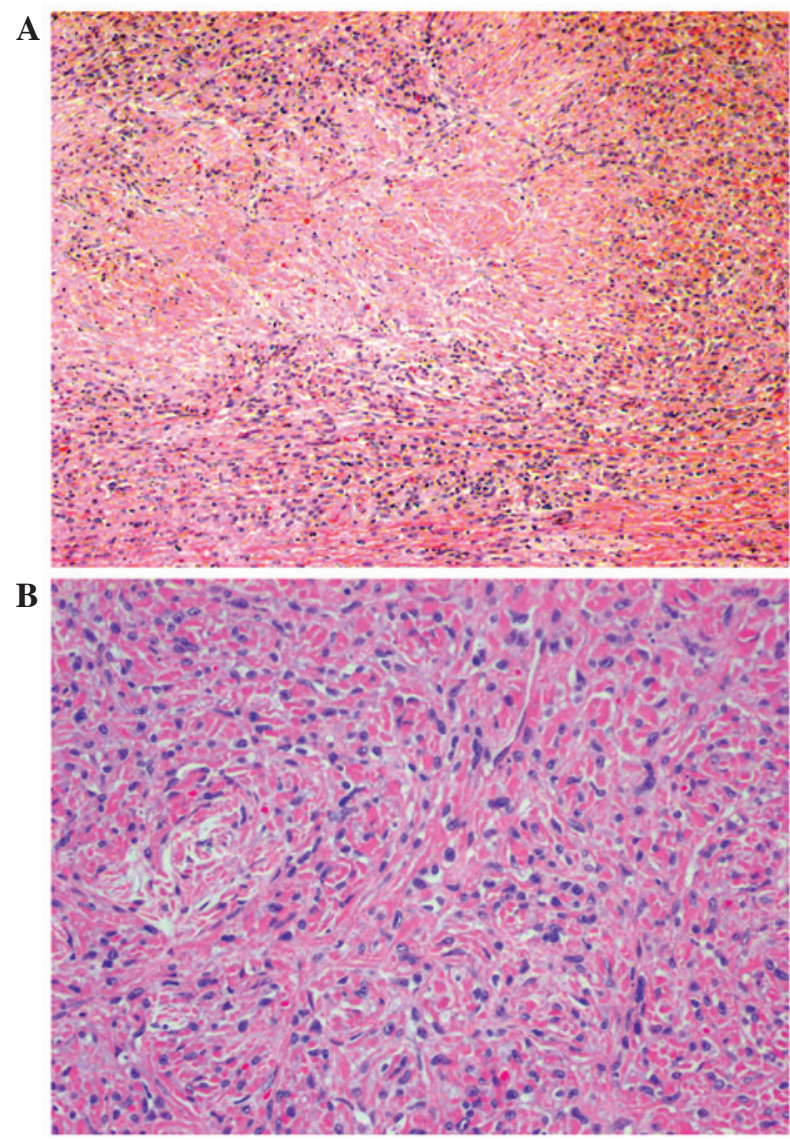

Figure 4. Histological images. (A) The tumor consisted of extensive areas of necrosis (hematoxylin and eosin staining; magnification, x200). (B) Cells were arranged in nests or clusters (hematoxylin and eosin staining; magnification, $\mathrm{x} 400)$.

\section{Discussion}

SEF is a rare yet distinct tumor, which was previously considered to be a low-grade variant of fibrosarcoma with 
low cellularity, mild pleomorphy, scarce mitotic figures and a densely sclerotic hyaline matrix $(1,2)$. A previous systematic review of 90 cases of SEF suggested a local recurrence rate of $36 \%$, a distant metastasis rate of $83 \%$, and a mortality rate of $34 \%$ from the disease after a mean of 46 months (3). However, a follow-up study of $\geq 1$ year in 14 cases revealed local recurrence, metastasis and mortality rates of 50, 86 and $57 \%$, respectively, suggesting a higher degree of malignancy (2). Subsequently, a small number of case reports verified that SEF was a clinically high-grade tumor with full malignant potential (4-9).

The skull is an extremely infrequent location for the development of SEF. Since it was first described in 1995, only 3 cases of skull SEF have been reported in the English literature (Table I) (2). The current case represents the 4th reported case of skull SEF, and resembles the other reported cases with regard to its clinical course. These 3 cases combined with the present case indicate that SEF in the skull tends to have aggressive behavior, leading to a poor prognosis.

Radiological findings, although scarce in the literature, were distinctive in the current case. The imaging findings demonstrated a well-defined, heterogeneous, intracranial, calvarial and extracalvarial mass with bone destruction. The osteolytic lesion presented sharp borders, a lack of bony sclerosis and a paucity of periosteal reaction. The adjacent brain and venous sinus were invaded. These appearances may reflect the malignant biological behavior of the tumor. On T2-weighted MRI without enhancement, irregular areas of low signal intensity were visible, a characteristic which may be observed in areas of decreased cellularity and dense fibrous tissue or collagen deposition (10). High signal intensity on T2-weighted images without enhancement is considered to indicate necrosis $(11,12)$. Intense perilesional enhancement of the tumor-adjacent brain region on gadolinium-enhanced MR images may be associated with histopathological changes, which include cellular and vascular proliferation, peritumoral desmoplastic reaction and inflammatory cell infiltration. This enhancement pattern may also be indicative of malignant tumors (13). Therefore, in the current case, imaging findings successfully suggested a tumor of high malignancy containing necrosis and fibrous tissue.

Although radiology may provide biological and histopathological information relating to SEF, the radiological differential diagnosis of skull SEF is challenging due to its rarity. A variety of malignant neoplasms in this site must be considered if an intracranial, calvarial and extracalvarial mass is detected in the occiput; such neoplasms include malignant meningioma, metastatic disease, osteosarcoma, plasmacytoma, chondrosarcoma, malignant fibrous histiocytoma and bone Langerhans cell histiocytosis $(14,15)$.

In summary, the current study reports an extremely rare instance of SEF arising within the occipital bone and simulating a high-grade tumor. Imaging features may provide important biological and histopathological information to make an accurate diagnosis. Radiologists must consider SEF as a possible diagnosis for a patient presenting with a slowly enlarging mass in this location that radiologically appears as a malignant tumor with necrosis and fibrous tissue, and exhibits an intense perilesional enhancement pattern.

\section{References}

1. Meis-Kindblom JM, Kindblom LG and Enzinger FM: Sclerosing epithelioid fibrosarcoma: A variant of fibrosarcoma simulating carcinoma. Am J Surg Pathol 19: 979-993, 1995.

2. Antonescu CR, Rosenblum MK, Pereira P, Nascimento AG and Woodruff JM: Sclerosing epithelioid fibrosarcoma. A study of 16 cases and confirmation of a clinicopathologically distinct tumor. Am J Surg Pathol 25: 699-709, 2001.

3. Ossendorf C, Studer GM, Bode B and Fuchs B: Sclerosing epithelioid fibrosarcoma: Case presentation and a systematic review. Clin Orthop Relat Res 466: 1485-1491, 2008.

4. Elkins CT and Wakely PE Jr: Sclerosing epithelioid fibrosarcoma of the oral cavity. Head Neck Pathol 5: 428-431, 2011.

5. Bai S, Jhala N, Adsay NV and Wei S: Sclerosing epithelioid fibrosarcoma of the pancreas. Ann Diagn Pathol 17: 214-216, 2013.

6. Chow LT, Lui YH, Kumta SM and Allen PW: Primary sclerosing epithelioid fibrosarcoma of the sacrum: A case report and review of the literature. J Clin Pathol 57: 90-94, 2004.

7. Tomimaru Y, Nagano H, Marubashi S, Kobayashi S, Eguchi H, Takeda Y, Tanemura M, Kitagawa T, Umeshita K, Hashimoto N, et al: Sclerosing epithelioid fibrosarcoma of the liver infiltrating the inferior vena cava. World J Gastroenterol 15: 4204-4208, 2009.

8. Folk GS, Williams SB, Foss RB and Fanburg-Smith JC: Oral and Maxillofacial sclerosing epithelioid fibroscarcoma: Report of five cases. Head Neck Pathol 1: 13-20, 2007.

9. Grunewald TG, von Luettichau I, Weirich G, Wawer A, Behrends U, Prodinger PM, Jundt G, Bielack SS, Gradinger R and Burdach S: Sclerosing epithelioid fibrosarcoma of the bone: A case report of high resistance to chemotherapy and a survey of the literature. Sarcoma 2010: 431627, 2010.

10. Christensen DR, Ramsamooj R and Gilbert TJ: Sclerosing epithelioid fiberosarcoma: Short T2 on MR imaging. Skeletal Radiol 26: 619-621, 1997.

11. Ulaner G, Hwang S, Lefkowitz RA, Landa J and Panicek DM.: Musculoskeletal tumors and tumor-like conditions: Common and avoidable pitfalls at imaging in patients with known or suspected cancer: Part A: Benign conditions that may mimic malignancy. Int Orthop 37: 871-876, 2013.

12. Ulaner G, Hwang S, Landa J, Lefkowitz RA and Panicek DM: Musculoskeletal tumours and tumour-like conditions: Common and avoidable pitfalls at imaging in patients with known or suspected cancer: Part B: Malignant mimics of benign tumours. Int Orthop 37: 877-882, 2013.

13. Semelka RC, Hussain SM, Marcos HB and Woosley JT: Perilesional enhancement of hepatic metastases: Correlation between MR imaging and histopathologic findings - initial observations. Radiology 215: 89-94, 2000.

14. Gangadhar K, Santhosh D: Radiopathological evaluation of primary malignant skull tumors: A review. Clin Neurol Neurosurg 114: 833-839, 2012.

15. Mitsuya K1, Nakasu Y, Horiguchi S, Harada H, Nishimura T, Yuen S, Asakura K and Endo M: Metastatic skull tumors: MRI features and a new conventional Classification. J Neurooncol 104: 239-245, 2011. 